\title{
HLA Class I Histocompatibility Antigen, Alpha Chain F
}

National Cancer Institute

\section{Source}

National Cancer Institute. HLA Class I Histocompatibility Antigen, Alpha Chain F. NCI

Thesaurus. Code C124892.

HLA class I histocompatibility antigen, alpha chain F (346 aa, 39 kDa) is encoded by the human HLA-F gene. This protein is involved in antigen presentation. 